\title{
High efficiency preparation of standard grade $\gamma$-tocopherol in plant-scale and its antioxidant activity
}

\author{
Yaping $\mathrm{Li}^{1}$, Linshang Zhang ${ }^{1}$, Zhide Wang ${ }^{1}$, Yanlan $\mathrm{Bi}^{2}$, and Dan Peng ${ }^{1}$ \\ ${ }^{1}$ Affiliation not available \\ ${ }^{2}$ Henan University of Technology
}

May 11, 2021

\begin{abstract}
Natural standard grade $\gamma$-tocopherol are of great interest due to its good antioxidant activity and special pharmacological functions. This study separated and purified $\gamma$-tocopherol from mixed tocopherols using eco-friendly and low toxicity solvents. $0.28 \mathrm{~g} \gamma$-tocopherol was obtained per performance with a purity of $98.89 \pm 0.68 \%$ and a recovery yield of $93.23 \pm 0.89 \%$. The purification conditions were as follows: elution solvent n-hexane/ethyl acetate 94.5:5.5 (v/v), sample load size 0.5 g, a column height to diameter ratio of $16: 1$ and an elution rate of $2 \mathrm{~mL} / \mathrm{min}$. The purity and structure of $\gamma$-tocopherol was confirmed by HPLC, GC/MS and NMR. The adsorption isotherm of $\gamma$-tocopherol on silica gel (200-300 mesh) fitted the Langmuir isotherm model well. The antioxidant activity analysis showed that $\gamma$-tocopherol had the strongest antioxidant activity followed by $\delta$-tocopherol and $\alpha$-tocopherol. This study provides an economically attractive solution for the production of natural standard grade $\gamma$-tocopherol.
\end{abstract}


$\nu \tau \iota \mathrm{\xi} \iota \delta \alpha \nu \tau \alpha \varsigma \tau \iota \tau \psi$

Yaping Li, Linshang Zhang, Zhide Wang, Yanlan Bi*, Dan Peng

College of Food Science and Engineering, Henan University of Technology, Zhengzhou 450001, China

*Corresponding author. E-mail: bylzry@126.com, Tel/Fax: +86-0371-67756022

\begin{abstract}
Natural standard grade $\gamma$-tocopherol are of great interest due to its good antioxidant activity and special pharmacological functions. This study separated and purified $\gamma$-tocopherol from mixed tocopherols using eco-friendly and low toxicity solvents. $0.28 \mathrm{~g} \gamma$-tocopherol was obtained per performance with a purity of $98.89 \pm 0.68 \%$ and a recovery yield of $93.23 \pm 0.89 \%$. The purification conditions were as follows: elution solvent n-hexane/ethyl acetate 94.5:5.5 (v/v), sample load size $0.5 \mathrm{~g}$, a column height to diameter ratio of 16:1 and an elution rate of $2 \mathrm{~mL} / \mathrm{min}$. The purity and structure of $\gamma$-tocopherol was confirmed by HPLC, GC/MS and NMR. The adsorption isotherm of $\gamma$-tocopherol on silica gel (200-300 mesh) fitted the Langmuir isotherm model well. The antioxidant activity analysis showed that $\gamma$-tocopherol had the strongest antioxidant activity followed by $\delta$-tocopherol and $\alpha$-tocopherol. This study provides an economically attractive solution for the production of natural standard grade $\gamma$-tocopherol.
\end{abstract}

Key words: standard grade $\gamma$-tocopherol; low toxicity solvents; purification; silica gel column chromatography; antioxidant activity

\section{Introduction}

Natural standard grade $\gamma$-tocopherol are of great interest due to its good antioxidant activity and special pharmacological functions. For instance, high-purity natural $\gamma$-tocopherol can significantly decrease tumor 
multiplicity induced by AOM, while mixed tocopherols cannot (Jiang et al. 2013). $\gamma$-tocopherol was also found to be able to induce the apoptosis of colorectal cancer cells in comparison to $\alpha$-tocopherol when used in conjunction with lovastatin (Braunrath et al. 2010). In addition, $\gamma$-tocopherol can protect edible oil and oil-rich foods from oxidization (Braunrath et al. 2010; Broznić et al. 2016). However, at present, high-purity natural $\gamma$-tocopherol is mainly sold in the form of standard at a high price (20000 RMB/g, Sigma) indicating the short of mature and economically feasible $\gamma$-tocopherol production method. Therefore, it is of great necessity to find an economically feasible method to obtain natural standard grade $\gamma$-tocopherol.

Currently, numerous studies focused on obtaining mixed tocopherol from deodorizing distillate (Hiromori et al. 2016; Ito et al. 2007; Zhou et al. 2009). Few studies paid attention to the separation and purification of $\gamma$-tocopherol. Tocopherol monomers was separated from soybean Vitamin E concentrate using low-pressure column chromatography with cyclohexane-ethanol as eluent (Wan et al. 2008). Under optimal operating conditions, the purity of $\gamma$-tocopherol was increased from $31.6 \%$ to $91.23 \%$. Nevertheless, the purity of $\gamma$-tocopherol was not up to the standard grade and its recovery was only about $30 \%$. A semi-prepared liquid chromatography method has been developed to separate four tocopherol monomers from the mixture of soybean oil and wheat germ oil (Tai-Sun and Godber 1994). $\gamma$-tocopherol could be well separated from $\alpha$-, $\beta$ - and $\delta$-tocopherol and the purity of $\gamma$-tocopherol were around 99\% (Tai-Sun and Godber 1994). But this method used toxic tetrahydrofuran which is not eco-friendly (Joshi and Adhikari 2019). The mass of separation was so small that only $28.8 \mathrm{mg}$ samples can be isolated at one time suggesting that this method was not suitable for the plant scale. Therefore, further studies are required to shed light on this issue.

This study intended to prepare natural standard grade $\gamma$-tocopherol using eco-friendly and low toxicity solvents (n-hexane, ethyl acetate). The adsorption behavior of $\gamma$-tocopherol on silica gel was discussed, which provided numerical support for the preparation of high-purity $\gamma$-tocopherol. Additionally, we compared the antioxidant activity of the purified $\gamma$-tocopherol with $\alpha$ - and $\delta$-tocopherol using lard as model fat.

\section{Materials and methods}

\subsection{Materials}

Samples of mixed tocopherols $(7.17 \% \alpha$-tocopherol, $1.47 \% \beta$-tocopherol, $60.04 \% \gamma$-tocopherol, $24.41 \% \delta$ tocopherol, $6.98 \%$ others) were purchased from Healthful Biotechnology Co., Ltd. (Xi'an, China). Fresh refined lard (acid value $0.14 \mathrm{mg} \mathrm{KOH} / \mathrm{g}$, peroxide value $0.39 \mathrm{mmol} / \mathrm{kg}$ ) without any antioxidants was obtained from Jiuyuan Co., Ltd. (Tianjin, China). Standards of $\alpha$-tocopherol (purity $>98.0 \%$ ), $\gamma$-tocopherol (purity $>98.0 \%$ ) and $\delta$-tocopherol (purity > 98.0\%) were purchased from Aladdin Bio-Chem Technology Co., Ltd. (Shanghai, China). Silica gel (200-300 mesh, irregular) used for column chromatography and silica G plates $(10 \times 10 \mathrm{~cm})$ were obtained from Haiyang Chemical Group Co., Ltd. (Qingdao, China). Quartz sand (silicon dioxide, 40-80 mesh, irregular) was purchased from Kemiou Chemical Reagent Co., Ltd. (Tianjin, China). All chemicals and solvents used were of analytical or HPLC grade.

\subsection{Methods}

\subsubsection{Analysis of mixed tocopherols}

Thin-layer chromatography (TLC) was employed to perform a qualitative analysis of the composition of mixed tocopherols samples. A mixed tocopherols sample was loaded on a TLC plate of silica gel for fractionation. A mixture of chloroform-ethyl acetate $(94: 6, \mathrm{v} / \mathrm{v})$ was chosen to be the developing solvent, and the iodine vapor was used as the coloring reagent. These three tocopherols and impurities were identified using $\alpha-, \beta-, \gamma-, \delta$-tocopherol and fatty acid methyl ester standards. Quantitative analysis of mixed tocopherols and their monomers were determined by high performance liquid chromatography (HPLC) using the AOCS method specified in Chapter Ce 8-89.

\subsubsection{Adsorption isotherms}

Pre-weighted $0.8 \mathrm{~g}$ of activated silica gel (200-300 mesh) were added into $20 \mathrm{~mL} \gamma$-tocopherol solutions with different initial concentrations, the conical flasks with cover were shaken $\left(25^{\circ} \mathrm{C}, 120 \mathrm{rpm}\right)$ until adsorption 
equilibrium was reached. The initial and equilibrium concentrations of $\gamma$-tocopherol solutions were analyzed by HPLC. The adsorption capacity of $\gamma$-tocopherol on silica gel was calculated according to the following equation (1). Langmuir and Freundlich models were employed to describe the adsorption behaviors.

$$
Q_{e}=\frac{\left(C_{0}-C_{e}\right) \times V}{M}
$$

Langmuir equation:

$$
Q_{e}=\frac{Q_{m} K_{L} C_{e}}{1+K_{L} C_{e}}
$$

Freundlich equation:

$$
Q_{e}=K_{F} C_{e}^{\frac{1}{n}}
$$

Where, $Q_{e}$ refers to the adsorption capacity (mg/g silica gel). $C_{0}$ and $C_{e}$ stand for the initial concentration and equilibrium concentrations of $\gamma$-tocopherol $(\mathrm{mg} / \mathrm{mL})$, respectively. $V$ refers to the volume of the initial sample solution $(\mathrm{mL})$, and $M$ represents the weight of the tested adsorbent (g). $Q_{m}$ stands for the theoretically calculated maximum adsorption capacity $(\mathrm{mg} / \mathrm{g}) . K_{L}$ is the Langmuir constant. $K_{F}$ and $\mathrm{n}$ are both the Freundlich constants.



The pre-weighed mixed tocopherol sample was dissolved in three $\mathrm{mL}$ of hexane to form a homogeneous solution which was then loaded onto a chromatographic column (length and diameter, $60 \times 3 \mathrm{~cm}$ ) packed with silica gel (200-300 mesh). Elution solvent was comprised of n-hexane and ethyl acetate. Elution flow rate was controlled by a constant flow pump, and a UV detector (wavelength, $290 \mathrm{~nm}$ ) was employed to monitor the elution processes. Elution fractions were collected in test tubes and analyzed by using TLC.

Elution fractions containing only $\gamma$-tocopherol were combined into a single mixture and the organic solvents were removed using a rotary evaporator (IKA, Germany) under reduced pressure. The amount of purified $\gamma$-tocopherol was calculated using mass balance, and the purity of $\gamma$-tocopherol was analyzed by HPLC according to the method above mentioned. The recovery yield and purity of $\gamma$-tocopherol were calculated according to the following equations, respectively.

$$
\begin{aligned}
& P(\%)=\frac{C \times V \times 10^{-6}}{W} \times 100 \% \\
& R(\%)=\frac{W \times P}{L \times B} \times 100 \%
\end{aligned}
$$

Where $C$ is the concentration of purified $\gamma$-tocopherol $(\mu \mathrm{g} / \mathrm{mL}) . V$ is the volume of the purified $\gamma$-tocopherol solution (mL). $W$ is the mass of purified $\gamma$-tocopherol (g), $P$ represents the purity of $\gamma$-tocopherol (\%), and $B$ refers to the $\gamma$-tocopherol content of mixed tocopherols $(\mathrm{g} / 100 \mathrm{~g})$, and $\mathrm{L}$ is the loading mass of column chromatography $(\mathrm{g})$.

\subsubsection{Dynamic adsorption and desorption experiments on silica gel column}

Column chromatography was performed under the optimal test conditions according to section 2.2.3, and the concentrations of $\alpha-, \gamma-$, and $\delta$-tocopherol in each fraction were determined by HPLC.

\subsubsection{Characterization of purified product}

2.2.5.1 TLC analysis of purified $\gamma$-tocopherol 
The conditions of TLC analysis were in accordance with the methods described in section 2.2.1.

2.2.5.2 HPLC analysis of purified $\gamma$-tocopherol

The conditions of HPLC analysis were same to the methods we mentioned in section 2.2.1.

2.2.5.3 GC/MS analysis of purified $\gamma$-tocopherol

GC7890 with 5975N mass spectrometer (Agilent Technologies, Palo Alto, CA, USA) was employed to identified the structure of purified $\gamma$-tocopherol. And the method of Bartosińska et al. (Bartosińska et al. 2016) was used with modification. The conditions of GC/MS analysis were as follows: one microlitre of purified $\gamma$-tocopherol samples $(5 \mu \mathrm{g} / \mathrm{mL})$ were injected in split mode. The split radio was 25:1. The samples were separated using an HP-5 MS capillary column $(30 \mathrm{~m} \times 0.25 \mathrm{~mm}, 0.25 \mu \mathrm{m}$ film thickness; J\&W Scientific, Folsom, CA, USA). Helium was used as the carrier gas at a rate of $1.0 \mathrm{~mL} / \mathrm{min}(23.441 \mathrm{psi})$. The injector and detector temperature were 280 and $300{ }^{\circ} \mathrm{C}$, respectively. Column oven temperature was set at $100{ }^{\circ} \mathrm{C}$ for $1 \mathrm{~min}$, then a temperature gradient program at $50{ }^{\circ} \mathrm{C} / \mathrm{min}$ up to $220^{\circ} \mathrm{C}$ for $2 \mathrm{~min}$, and $10{ }^{\circ} \mathrm{C} / \mathrm{min}$ up to $285{ }^{\circ} \mathrm{C}$ for $15 \mathrm{~min}$. MS detector $230{ }^{\circ} \mathrm{C}$, MS quadrupole $150{ }^{\circ} \mathrm{C}$, electron ionization energy $70 \mathrm{eV}$, and mass range $40-500 \mathrm{~m} / \mathrm{z}$.

2.2.5.4 NMR analysis of purified $\gamma$-tocopherol

All NMR spectra of purified $\gamma$-tocopherol were obtained using a Bruker $500 \mathrm{MHz}$ Avance III NMR spectrometer (Bruker, Rheinstetten, Germany) using a $5 \mathrm{~mm}$ switchable, broadband probe. All spectra were obtained in deuterochloroform at ambient temperature $\left(30^{\circ} \mathrm{C}\right.$ in the probe). ${ }^{1} \mathrm{H}$-NMR spectra were obtained using a spectral width of $13889 \mathrm{~Hz}, 2$ sweeps, 128 scans and a pulse angle of $30^{\circ}$. The ${ }^{13} \mathrm{C}-\mathrm{NMR}$ spectra were acquired under the following conditions: combined pulse decoupling, 4 sweeps, 1024 scans and a pulse angle of $30^{\circ}$.



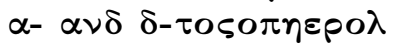

Lard was heated in a water bath at $50{ }^{\circ} \mathrm{C}$ until it liquified completely. $\alpha$-, $\gamma$-, and $\delta$-tocopherol with concentrations of $0,50,150,250,500$, and $1000 \mathrm{mg} / \mathrm{kg}$ were added to lard, respectively. Oxidative stability tests were subsequently performed at $120^{\circ} \mathrm{C}$ using Rancimat (Upadhyay and Mishra 2016) (892 model, Metrohm, Switzerland) with an air velocity of $20 \mathrm{~L} / \mathrm{h}$. The stability of lard sample was expressed in terms of Induction Period (IP) value.

\subsection{Statistical analysis}

All experiments were performed at least in duplicate. All data were presented as mean \pm standard deviation (SD). The significance of difference was assessed using SPSS 16.0 (SPSS Inc., Chicago, IL, USA). Differences were considered significant when the $\mathrm{p}$ value was $<0.05$.

\section{Results and Discussion}

\subsection{Analysis of mixed tocopherols}

As shown in Fig 2a, the components of mixed tocopherols are four kinds of tocopherol monomers and some impurities with a less polarity than $\alpha$-tocopherol. And we all know that the mixed tocopherols are mainly obtained by molecular distillation under reduced pressure and high temperature after esterification of fatty acids, triglyceride and crystallization of sterols (Ito et al. 2007). After comparison with the standard substances, we speculated that the impurities may be fatty acid methyl ester. The four tocopherols and impurities are thereby separated in the following order: $\delta$-T, $(\beta+\gamma)$-, $\alpha$-tocopherol and impurities with increasing Rf values: $0.69,0.79,0.90,0.95$, this order showed that the polarity of our target $\gamma$ - tocopherol is between $\delta$ - and $\alpha$-tocopherol. In order to obtain the high-purity target $\gamma$-tocopherol, we have to remove not only impurities, but also $\alpha$ - and $\delta$-tocopherol, so it is difficult to separate target substance for the reasons given above. The total tocopherol content in mixed tocopherol was $91.62 \%$, with the contents of $\alpha_{-}^{-}, \beta-, \gamma^{-}$ 
and $\delta$ - tocopherol were $7.17 \%, 1.47 \%, 60.04 \%$ and $24.41 \%$, respectively. And the impurities were around $6.91 \%$.

\subsection{Adsorption isotherms}

The adsorption isotherm is one of the most important approaches to illustrate the mechanism of the adsorption systems. The adsorption isotherms of $\gamma$-tocopherol on silica gel were fitted using Langmuir model (Fig. 3a) and Freundlich model (Fig. 3b), respectively. The parameters of Langmuir and Freundlich models were summarized in Table 1.

From Fig. 3a and Fig. 3b, the Langmuir model can be considered as a better model for describing adsorption equilibrium due to its higher correlation coefficient $\left(\mathrm{R}^{2}=0.9944\right)$, followed by the Freundlich model with an $\mathrm{R}^{2}$ value of 0.8997 . The value of $\mathrm{Q}_{\mathrm{m}}$ gives the maximum monolayer adsorption capacity of the adsorbent. In most cases, the constant $\mathrm{n}$ of the Freundlich equation shows the adsorption intensity, and the $\mathrm{n}$ value between 1 and 10 shows beneficial adsorption (Duran et al. 2011). The $\mathrm{n}$ value of the adsorption model was 4.36 , which indicated that the adsorption on silica gel (200-300 mesh) can easily take place.

\section{$3.3 \mathrm{E} \varphi \varphi \varepsilon \varsigma \tau$ o}

The mixed tocopherols were separated by thin-layer chromatography (TLC) first with a mixture of n-hexane, anhydrous ethanol, isopropyl alcohol, tetrahydrofuran and ethyl acetate as the developing agent. After a large number of tests, the mixed solution of n-hexane and ethyl acetate was finally chosen as the eluent for column chromatography tests.

Mixed tocopherols were separated and purified using column chromatography. As shown in Fig. 4a, we could know that the eluent ratio had a great influence on the purification of $\gamma$-tocopherol. With the increase of the volume ratio of n-hexane to ethyl acetate, the polarity of eluent decreased gradually, and the purity and yield of $\gamma$-tocopherol increased at first and then decreased. When the volume ratio of n-hexane to ethyl acetate increased from 88.5:11.5 to 94.5:5.5, the purity and recovery rate of $\gamma$-tocopherol increased from $(76.22 \pm 3.81) \%$ and $(43.08 \pm 4.31) \%$ to $(90.06 \pm 1.09) \%$ and $(82.98 \pm 2.75) \%$, respectively. This may be due to the fact that when the eluent ratio is less than 94.5:5.5, the polarity of eluent was too strong to make $\gamma$-tocopherol be separated from other tocopherol monomers. When the volume ratio of n-hexane to ethyl acetate was more than 94.5:5.5, the polarity of eluent is too weak, and the time of separation process was too long, which caused the material diffused seriously in the column, so the separation effect is poor. For example, when the volume ratio of n-hexane to ethyl acetate was 97.5:2.5, the purity and recovery yield of $\gamma$-tocopherol were $(76.06 \pm 0.98) \%$ and $(64.16 \pm 3.08) \%$, respectively. From what has been discussed above, the hexane/ethyl acetate eluent with a volume ratio of 94.5:5.5 was elected as the subsequent optimization tests.

The effects of loading amounts on the $\gamma$-tocopherol purification were shown in Fig. 4b. The purity and recovery rate of $\gamma$-tocopherol increased first and then decreased when the loading amounts of the sample increased from $0.25 \mathrm{~g}$ to $1.25 \mathrm{~g}$. The maximum purity and yield of $\boldsymbol{\gamma}$-tocopherol were $(98.49 \pm 0.29) \%$ and $(92.18 \pm 0.34) \%$, respectively (loading amounts $0.5 \mathrm{~g})$. Theoretically, when the other conditions of the column are certain, the maximum loading amounts is certain. Under the condition that the loading amounts was not overloaded, the larger the sample loading was, the better. But when the sample weight was $0.25 \mathrm{~g}$, which did not exceed the maximum loading amounts of chromatography column, however, the purity and recovery rate of $\gamma$-tocopherol were only $(56.97 \pm 0.23) \%$ and $(54.06 \pm 0.29) \%$ respectively. This can be explained by the fact that much material were adsorbed on the silica gel column, and only a small portion of the target product and most of the impurities were cleared off (Duran et al. 2011). When loading amounts of sample was more than $0.5 \mathrm{~g}$, the purity and recovery rate of $\gamma$-tocopherol were reduced gradually, for example, the purity and recovery rate of $1.25 \mathrm{~g}$ samples decreased by $(10.82 \pm 0.16) \%$ and $(41.09 \pm 0.30) \%$, respectively, compared with that of $0.5 \mathrm{~g}$ samples. This may be due to the sample overload, the chromatographic band of each component overlapped in the separation process, which resulted in poor separation effect (Chen et al. 2017). Therefore, $0.5 \mathrm{~g}$ was selected as the best loading amounts of sample. 
The ratio of column height to diameter was also an important factor, relative to the theoretical plate number of chromatography theory, therefore an appropriate ratio of column height to diameter(H/D) was really necessary for column chromatography. The effect of different ratios of column height to diameter (12:1, 14:1, 16:1, 18:1, 20:1) on the $\gamma$-tocopherol purification were shown in Fig. 4c. With the increase of the ratio of column height to diameter from 12:1 to 20:1, there was no significant change in the purity of $\gamma$-tocopherol ( $\mathrm{p}_{\dot{6} 0.05)}$, and the recovery rate of $\gamma$-tocopherol increased first and then decreased. When H/D value were 16:1 and 18:1, the purities and recovery yield of $\gamma$-tocopherol reached the maximum values, which were $(98.89 \pm 0.68) \%,(93.23 \pm 0.89) \%$ and $(98.49 \pm 0.29) \%,(92.18 \pm 0.34) \%$, respectively. There was no significant difference in purity and recovery between the two $(\mathrm{p}>0.05)$. When the $\mathrm{H} / \mathrm{D}$ values were $12: 1$ and 14:1, the recoveries of $\gamma$-tocopherol were only $(48.07 \pm 3.06) \%$ and $(70.14 \pm 1.88) \%$, the reason may be that when the ratio of column height to diameter was too small, there was not sufficient time to complete the adsorption resolution process for each component. When the H/D value was 20:1, the recovery rate of $\gamma$-tocopherol decreased, which may be due to the serious diffusion of the substance on the silica gel column. Therefore, a 16:1 ratio of column height to diameter was selected as the optimal ratio for the purification of $\gamma$-tocopherol.

An appropriate elution flow rate is crucial for attaining a good yield and elution capacity. The effects of elution flow rate on the $\gamma$-tocopherol purification were shown in Fig. 4d. The maximum purity $(98.89 \pm$ $0.68 \%)$ and recovery yield $(93.23 \pm 0.89 \%)$ of $\gamma$-tocopherol were obtained with the elution flow rate of 2.0 $\mathrm{mL} / \mathrm{min}$. When the elution flow rate was above $2.0 \mathrm{~mL} / \mathrm{min}$, the recovery yield of $\gamma$-tocopherol decreased significantly. The low separation efficiency can be explained by the fact that the flow was too fast to allow the components to complete adsorption or desorption during the purge process (Chen et al. 2017). Generally speaking, slow flow rate exerted a positive effect for adsorption process because adsorbate molecules had sufficient time to complete adsorption or desorption of the components (Liu et al. 2011). However, the separation time was much longer and resulted in diffusion of substances during the separation process with a slow flow rate (Wan et al. 2008).

The optimal purification conditions were determined as follows: elution solvents, n-hexane/ethyl acetate (94.5:5.5, v/v); loading amounts, $0.5 \mathrm{~g}$; the ratio of column height to diameter, 16:1; and elution flow rate, $2.0 \mathrm{~mL} / \mathrm{min}$. Under these optimized conditions, the purity and recovery yield of $\gamma$-tocopherol were $(98.89 \pm$ $0.68) \%$ and $(93.23 \pm 0.89) \%$, respectively.

\subsection{DynamicDesorption Tests}

The dynamic desorption process was described at the optimum experimental condition (Fig. S1). Results showed that the impurities were eluted first, and then the four tocopherols were eluted in the following order: $\alpha-T,(\beta+\gamma)$ and $\delta$-tocopherol. After six hours of elution, the impurities and $\alpha$-tocopherol were completely eluted, at which point $\gamma$-tocopherol appeared in the eluent and $\delta$-tocopherol appeared in the eluent 8.5 hours later. Therefore, the $\gamma$-tocopherol can be well separated by this method.

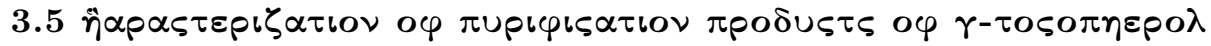

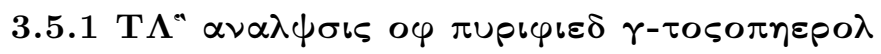

TLC was used to analyze the components of the purified $\gamma$-tocopherol, and compared it with the $\gamma$-tocopherol standard substances (Fig. 2b). Results showed that non- $\gamma$-tocopherol ( $\alpha$ - and $\delta$-tocopherol) and most of the impurities in the mixed tocopherols samples have been removed after one simple column chromatographic separation. And the spots on silica gel plate of purified $\gamma$-tocopherol was fewer than that of $\gamma$-tocopherol standard, which indicated that the purity of our purified $\gamma$-tocopherol was much higher than that of $\gamma$ tocopherol standard.

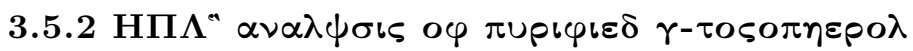

HPLC was used to further determine the purity of the purified $\gamma$-tocopherol (Fig. S2). Results showed that the major peak representing $\gamma$-tocopherol (relevant content: 98.86\%) was observed at a retention time of $12.68 \mathrm{~min}$, and the peak of $\beta$-tocopherol (relevant content: $0.96 \%$ ) was observed as a low intensity at a 
retention time of 11.23 min. A tiny peak (relevant content: $0.18 \%$ ) was observed at retention time of 4.02 min, which was caused by the impurities in solvent (used to dissolve tocopherol) and $\gamma$-tocopherol solution.

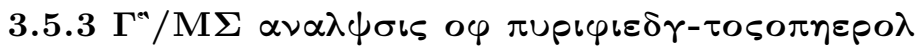

GC/MS was used to further clarify the chemical structures of $\gamma$-T and impurities in the purified $\gamma$-T (Fig 5, Table 2, Fig S3,). One strong peak (98.74\%) was observed in gas chromatographic curve (Fig S3). The ions of this peak were as follows: 43.0, 150.0, 151.0, 416.0, which was consist with other report indicating that high purity $\gamma$-T was obtained (Nagy et al. 2007). It was well known that $\beta$-tocopherol and $\gamma$-T yielded same ions (Fig $5 \mathrm{c}$, d), but $\gamma$-T owned relative high polarity, therefore, it was speculated that the peaks at the retention time of 15.33 and 15.07 were $\gamma$-T and $\beta$-tocopherol, respectively (Table 2). Two tiny peaks (relative contents: $0.07 \%$ and $0.09 \%$, respectively) were observed at $6.32 \mathrm{~min}$ and $9.83 \mathrm{~min}$, respectively. Based on their MS results (Table 2 and Fig $5 \mathrm{a}, \mathrm{b}$ ), molecular formulas of these compounds were determined to be $\mathrm{C}_{16} \mathrm{H}_{22} \mathrm{O}_{4}$ and $\mathrm{C}_{23} \mathrm{H}_{32} \mathrm{O}_{2}$, respectively. After referring to the mass spectral library, it was found that they were dibutyl phthalate and 2,2'-Methylenebis(6-tert-butyl-4-methylphenol), respectively. And these two compounds were all used in plastic products as plasticizers and anti-aging agents, respectively.



NMR was used to further identified the purified $\gamma$-T. The ${ }^{1} \mathrm{H}-\mathrm{NMR}$ and ${ }^{13} \mathrm{C}-\mathrm{NMR}$ spectra of purified $\gamma$ $\mathrm{T}$ were presented in Fig. S4 and Fig. S5, respectively. The chemical shift assignments of purified $\gamma$-T were summarized in Table 3. In ${ }^{1} \mathrm{H}-\mathrm{NMR}$ spectrum, three characteristic peaks $(\delta$ 4.225, 7.495 and 7.696) were observed, in addition to the characteristic peaks of $\gamma$-tocopherol. Combining the characteristic peaks, corresponding area of these peaks and the ${ }^{13} \mathrm{C}-\mathrm{NMR}$ spectra, it was seen that the structure of purified $\gamma$ tocopherol is consistent with that described in Fig. 1, which indicated that purified $\gamma$-tocopherol is of high purity.

 $\alpha \nu \delta \delta$ -}

The higher induction period (IP) value indicates the better oxidation stability of oil and the stronger antioxidant activity of the corresponding antioxidant.

The effects of $\alpha$-, $\gamma$ - and $\delta$-tocopherol at $0,50,150,250,500$ and $1000 \mathrm{mg} / \mathrm{kg}$ on the IP of lard at $120{ }^{\circ} \mathrm{C}$ were showed in Table 4. Results showed that the IP values of lard with $\gamma$-T at all concentrations (0-1000 $\mathrm{mg} / \mathrm{kg})$ were significantly prolonged at $120{ }^{\circ} \mathrm{C}$ compared with the control lard without $\gamma-\mathrm{T}(\mathrm{p}<0.05)$, and the IP values of lard gradually increased with the concentrations of $\gamma$-T increased from $50 \mathrm{mg} / \mathrm{kg}$ to 150 , 250,500 , and $1000 \mathrm{mg} / \mathrm{kg}(\mathrm{p}<0.05)$. The effect of $\alpha$ - and $\delta$-tocopherol on IP value of lard was similar to that of $\gamma$-tocopherol. However, at the same addition, the IP value of lard with $\gamma$-tocopherol was higher than that of the lard with $\delta$-tocopherol, and the IP value of lard with $\alpha$-tocopherol was lowest. This indicated that the antioxidant activity of $\gamma-T$ was strongest, followed by $\delta$-T and $\alpha$-T in lard.

Additionally, the antioxidant activities of $\alpha$-, $\gamma$ - and $\delta$-tocopherol were compared with that of the synthetic antioxidant BHT using Rancimat at $120{ }^{\circ} \mathrm{C}$ (Table 4). Results showed that the IP values of lard with $\alpha-, \gamma-$ and $\delta$-tocopherol of $200 \mathrm{mg} / \mathrm{kg}$ were $(4.59 \pm 0.04),(8.02 \pm 0.08)$ and $(6.48 \pm 0.11) \mathrm{h}$, respectively. This indicated that the antioxidant activity of $\gamma$-T was strongest among these three tocopherol monomers. The IP value of lard with $200 \mathrm{mg} / \mathrm{kg}$ BHT was $(4.27 \pm 0.16) \mathrm{h}$, which was significantly shorter than that of $\gamma$-tocopherol at the same addition $(\mathrm{p}<0.05)$. Even more, The IP value $(4.52 \pm 0.07) \mathrm{h}$ of lard with $50 \mathrm{mg} / \mathrm{kg} \gamma$-tocopherol was higher than that of lard with $200 \mathrm{mg} / \mathrm{kg}$ BHT $(\mathrm{p}<0.05)$. This indicated that the antioxidant capacity of $\gamma$-tocopherol at $50 \mathrm{mg} / \mathrm{kg}$ in lard was stronger than that of BHT at the maximum residue limit $(200 \mathrm{mg} / \mathrm{kg})$. Therefore, $\gamma$-tocopherol was a good choice to replace BHT in terms of human health and antioxidant capacity.

\section{Conclusion}

In this study, the separation and purification process of $\gamma$-tocopherol was optimized. Under the optimal conditions, the purity of $\gamma$-tocopherol reached $(98.38 \pm 0.68) \%$, and the yield was $(93.23 \pm 0.89) \%$. The 
method adopted in this study could obtain high-purity $\gamma$-tocopherol, and was simple and easy to operate and more eco-friendly, which can be performed in plant-scale and provide certain theoretical support for the production of $\gamma$-tocopherol. Furthermore, we compared the antioxidant activities of $\alpha-, \gamma$ - and $\delta$-tocopherol and found that $\gamma$-tocopherol had the best antioxidant activities among these three tocopherol monomers, our results could provide data supports for the further application of tocopherols.

\section{Acknowledgement}

This work was supported by the National Natural Science Foundation of China [grant numbers 31671818]

\section{References}

Bartosińska E, Buszewska-Forajta M, Siluk D (2016). GC-MS and LC-MS approaches for determination of tocopherols and tocotrienols in biological and food matrices. J Pharm Biomed Anal 127:156-169

Braunrath R, Isnardy B, Solar S, Elmadfa I (2010). Impact of $\alpha$-, $\gamma$-, and $\delta$-tocopherol on the radiation induced oxidation of rapeseed oil triacylglycerols. Radiat Phys Chem 79:764-769

Broznić D, Jurešić GČ, Milin Č (2016). Involvement of $\alpha$-, $\gamma$ - and $\delta$-tocopherol isomers from pumpkin (cucurbita pepo L.) seed oil or oil mixtures in the biphasic DPPH. disappearance kinetics. Food Technol Biotechnol 54:200-210

Chen S, Bi Y, Chen J, Wei M, Sun S, Chen J (2017). Separation, purification, and characterization of sterol fatty acid esters from lotus plumule. Eur J Lipid Sci Technol 119:1700139

Duran C, Ozdes D, Gundogdu A, Senturk HB (2011). Kinetics and isotherm analysis of basic dyes adsorption onto almond shell (Prunus dulcis ) as a low cost adsorbent. J Chem Eng Data 56:2136-2147

Hiromori K, Shibasaki-Kitakawa N, Nakashima K, Yonemoto T (2016). Novel simple process for tocopherols selective recovery from vegetable oils by adsorption and desorption with an anion-exchange resin. Food Chem 194:1-5

Ito VM, Batistella CB, Maciel MRW, Filho RM (2007). Optimization of tocopherol concentration process from soybean oil deodorized distillate using response surface methodology. Appl Biochem Biotechnol 137:885896

Jiang Q et al. (2013). Gamma-tocopherol attenuates moderate but not severe colitis and suppresses moderate colitis-promoted colon tumorigenesis in mice. Free Radic Biol Med 65:1069-1077

Joshi DR, Adhikari N (2019). An overview on common organic solvents and their toxicity J Pharm Res Int 28:1-18

Liu Y, Di D, Bai Q, Li J, Chen Z, Lou S, Ye H (2011). Preparative separation and purification of rebaudioside A from steviol glycosides using mixed-mode macroporous adsorption resins. J Agric Food Chem 59:9629-9636

Nagy K, Courtet-Compondu M-C, Holst B, Kussmann M (2007). Comprehensive analysis of vitamin E constituents in human plasma by liquid chromatography-mass spectrometry. Anal Chem 79:7087-7096 doi:10.1021/ac0708689

Tai-Sun S, Godber JS (1994). Isolation of four tocopherols and four tocotrienols from a variety of natural sources by semi-preparative high-performance liquid chromatography. J Chromatogr A 678:49-58

Upadhyay R, Mishra HN (2016). Effect of relative humidity and light conditions on the oxidative stability of sunflower oil blends stabilised with synthetic and natural antioxidants. Int J Food Sci Tech 51:293-299

Wan J, Zhang W, Jiang B, Guo Y, Hu C (2008). Separation of individual tocopherols from soybean distillate by low pressure column chromatography. J Am Oil Chem Soc 85:331-338

Zhou W-W, Qin D-H, Qian J-Q (2009). Optimisation of enzymatic pretreatment of soybean oil deodoriser distillate for concentration of tocopherols. Int J Food Sci Tech 44:1429-1437 
Table 1 Isotherm model constants and correlation coefficients for sorption of $\gamma$ - tocopherol on silica gel (200 300mesh)

\begin{tabular}{llll}
\hline Isotherm & Linear fitting formula & Parameters & Values \\
\hline Langmuir & $\mathrm{C}_{\mathrm{e}} / \mathrm{Q}_{\mathrm{e}}=0.0041 \mathrm{C}_{\mathrm{e}}+0.0027$ & $\mathrm{Q}_{\mathrm{m}}$ & 243.90 \\
& & $\mathrm{~K}_{\mathrm{L}}(\mathrm{mL} / \mathrm{mg})$ & 1.518 \\
& & $\mathrm{R}^{2}$ & 0.9944 \\
Freundlich & $\operatorname{lnQ}_{\mathrm{e}}=0.2294 \operatorname{lnC}_{\mathrm{e}}+4.9417$ & $\mathrm{~K}_{\mathrm{F}}\left[(\mathrm{mg} / \mathrm{g})(\mathrm{mL} / \mathrm{mg})^{1 / \mathrm{n}}\right]$ & 140.01 \\
& & $\mathrm{n}$ & 4.36 \\
& & $\mathrm{R}^{2}$ & 0.8997 \\
\hline
\end{tabular}

Table 2 Molecular masses and $\mathrm{m} / \mathrm{z}$ ratios of the components in purified $\gamma$ - $\mathrm{T}$ in mass spectrum

\begin{tabular}{llll}
\hline Retention time $(\mathrm{min})$ & Molecular masses & $\mathrm{m} / \mathrm{z}$ & Relative content $(\%)$ \\
\hline 6.32 & 278 & $56.0,76.0,104.0,149.0,150.0$ & 0.07 \\
9.83 & 340 & $149.0,161.0,164.0,177.0,340.0$ & 0.09 \\
15.07 & 416 & $43.0,150.0,151.0,416.0$ & 1.10 \\
15.33 & 416 & $43.0,150.0,151.0,416.0$ & 98.74 \\
\hline
\end{tabular}

Table $3{ }^{13} \mathrm{C}-,{ }^{1} \mathrm{H}-\mathrm{NMR}$ chemical shift assignments for the $\gamma$ - tocopherol purification product

\begin{tabular}{ll}
\hline Purified $\gamma$-tocopherol & chromatographic parameter \\
\hline${ }^{13} \mathrm{C}-\mathrm{NMR}\left(\mathrm{CC}_{13} \mathrm{D}\right)$ & $\delta 146.18(8 \mathrm{aC}) ; \delta 145.74(6 \mathrm{C}) ; \delta 125.79(8 \mathrm{C}) ;$ \\
& $\delta 121.57(7 \mathrm{C}) ; \delta 118.30(5 \mathrm{C}) ; \delta 112.12(4 \mathrm{aC}) ;$ \\
& $\delta 75.46(2 \mathrm{C}) ; \delta 39.97\left(1{ }^{\prime} \mathrm{C}\right) ; \delta 39.37\left(11^{\prime}-\mathrm{C}\right) ;$ \\
& $\delta 37.42\left(3^{\prime}-\mathrm{C}\right) ; \delta 37.39\left(5^{\prime}-\mathrm{C}\right) ; \delta 37.25\left(7^{\prime}-\mathrm{C}\right) ;$ \\
& $\delta 37.21\left(9^{\prime}-\mathrm{C}\right) ; \delta 32.76\left(4^{\prime}-\mathrm{C}\right) ; \delta 32.68\left(8^{\prime}-\mathrm{C}\right) ;$ \\
& $\delta 31.0(3-\mathrm{C}) ; \delta 27.90\left(12^{\prime} \mathrm{C}\right) ; \delta 24.78\left(10^{\prime}-\mathrm{C}\right) ;$ \\
& $\delta 24.40\left(6^{\prime}-\mathrm{C}\right) ; \delta 24.0(2-\mathrm{C}-\mathrm{C}) ; \delta 22.70(12 ' \mathrm{C}-\mathrm{C}) ;$ \\
& $\delta 22.68\left(13^{\prime}-\mathrm{C}\right) ; \delta 22.26\left(2^{\prime}-\mathrm{C}\right) ; \delta 20.98(4-\mathrm{C}) ;$ \\
& $\delta 19.72\left(4^{\prime}-\mathrm{C}-\mathrm{C}\right) ; \delta 19.62\left(8^{\prime}-\mathrm{C}-\mathrm{C}\right) ; \delta 11.86(7-\mathrm{C}-\mathrm{C}) ;$ \\
& $\delta 11.86(8 \mathrm{C}-\mathrm{C})$ \\
& $\delta 6.30(5 \mathrm{H}) ; \delta 4.73(6-\mathrm{OH}) ; \delta 2.62-2.62(4 \mathrm{H}) ;$ \\
& $\delta 2.11-2.09(7,8-\mathrm{CH} 3) ; \delta 1.75-1.67(3 \mathrm{H}) ;$ \\
& $\delta 1.52-1.50\left(12^{\prime} \mathrm{H}\right) ; \delta 1.52-1.49(1 ' \mathrm{H}) ;$ \\
& $\delta 1.25-1.49\left(2^{\prime}, 4^{\prime}, 6^{\prime}, 8^{\prime}, 10^{\prime}-\mathrm{CH} 2 ; 2-\mathrm{CH} 3\right) ; \delta 0.96-1.23\left(3^{\prime}\right.$, \\
& $\left.5^{\prime}, 7^{\prime}, 9^{\prime}-\mathrm{CH} 2\right) ; \delta 0.85-0.87\left(4{ }^{\prime}, 8^{\prime}, 12^{\prime}-\mathrm{CH} 3 ; 13 ' \mathrm{H}\right) ;$ \\
\hline
\end{tabular}

Table 4 The IP values of lard with $\alpha$-, $\gamma$ - and $\delta$-tocopherol at different concentrations $(0-1000 \mathrm{mg} / \mathrm{kg})$ at $120{ }^{\circ} \mathrm{C}$

\begin{tabular}{lllll}
\hline Concentration $(\mathrm{mg} / \mathrm{kg})$ & $\alpha$-tocopherol & $\gamma$-tocopherol & $\delta$-tocopherol & BHT \\
\hline 0 & $2.14 \pm 0.02^{\mathrm{f}, \mathrm{A}}$ & $2.14 \pm 0.02^{\mathrm{f}, \mathrm{A}}$ & $2.14 \pm 0.02^{\mathrm{g}, \mathrm{A}}$ & \\
50 & $3.49 \pm 0.09^{\mathrm{e}, \mathrm{B}}$ & $4.52 \pm 0.07^{\mathrm{e}, \mathrm{A}}$ & $3.59 \pm 0.04^{\mathrm{f}, \mathrm{B}}$ & \\
150 & $4.53 \pm 0.01^{\mathrm{d}, \mathrm{C}}$ & $7.20 \pm 0.12^{\mathrm{d}, \mathrm{A}}$ & $5.81 \pm 0.05^{\mathrm{e}, \mathrm{B}}$ & \\
200 & $4.59 \pm 0.04^{\mathrm{d}, \mathrm{C}}$ & $8.02 \pm 0.08^{\mathrm{c}, \mathrm{A}}$ & $6.48 \pm 0.11^{\mathrm{d}, \mathrm{B}}$ & $4.27 \pm 0.16^{\mathrm{C}}$
\end{tabular}




\begin{tabular}{|c|c|c|c|c|}
\hline Concentration $(\mathrm{mg} / \mathrm{kg})$ & $\alpha$-tocopherol & $\gamma$-tocopherol & 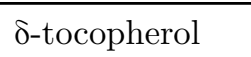 & BHT \\
\hline 250 & $4.81 \pm 0.11^{\mathrm{c}, \mathrm{C}}$ & $8.07 \pm 0.06^{\mathrm{c}, \mathrm{A}}$ & $7.12 \pm 0.01^{\mathrm{c}, \mathrm{B}}$ & \\
\hline 500 & $5.18 \pm 0.04$ b, C & $9.61 \pm 0.14^{\mathrm{b}, \mathrm{A}}$ & $9.04 \pm 0.00 \mathrm{~b}, \mathrm{~B}$ & \\
\hline 1000 & $5.51 \pm 0.04 \mathrm{a}, \mathrm{B}$ & $10.20 \pm 0.35$ a, A & $10.49 \pm 0.81$ a, A & \\
\hline
\end{tabular}

The results were expressed as mean $\pm \mathrm{SD}$, with two replications. Values within a column followed by the different letters are significantly different $(\mathrm{p}<0.05)$. Different capital letter indicated significantly different $(\mathrm{p}<0.05)$ within a row.

\section{Figure captions}

Fig. 1 Chemical structure of $\gamma$-tocopherol.

Fig. 2 Thin layer chromatography (TLC) of mixed tocopherol (a) and purified $\gamma$-tocopherol (b)

A, mixed tocopherols sample; B, a mixture of four tocopherol monomers; C, Fatty acid methyl esters (FAME); $\mathrm{D}$, the purified $\gamma$-tocopherol; E, $\gamma$-tocopherol standard.

Fig. 3 Langmuir (a) and Freundlich (b) model fitting adsorption isotherm diagram $\left(25{ }^{\circ} \mathrm{C}, 200^{\sim} 300\right.$ mesh)

Fig. 4 Effects of eluting factors on the separation process

(a) eluting agent, conditions: column height to diameter ratio $16: 1$, loading amount $0.5 \mathrm{~g}, 2.0 \mathrm{~mL} / \mathrm{min}$.

(b) loading amounts, conditions: n-hexane: ethyl acetate $(94.5: 5.5, \mathrm{v} / \mathrm{v})$, column height to diameter ratio $16: 1,2.0 \mathrm{~mL} / \mathrm{min}$.

(c) Ration of column height to diameter, conditions: n-hexane: ethyl acetate (94.5:5.5, v/v), loading amount $0.5 \mathrm{~g}, 2.0 \mathrm{~mL} / \mathrm{min}$.

(d) elution rate, conditions: n-hexane: ethyl acetate (94.5:5.5, v/v), ratio of column height to diameter 16:1, loading amount $0.5 \mathrm{~g}$.

Fig. 5 Mass spectrum of substances identified in the purified product. (a) impurity at $6.32 \mathrm{~min}$; (b) impurity at $9.83 \mathrm{~min}$; (c) $\beta$-tocopherol; (d) $\gamma$-tocopherol.

Fig. 1

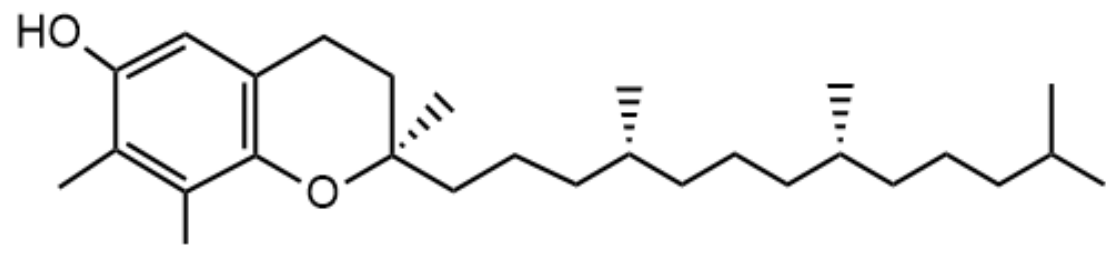

Fig. 2 


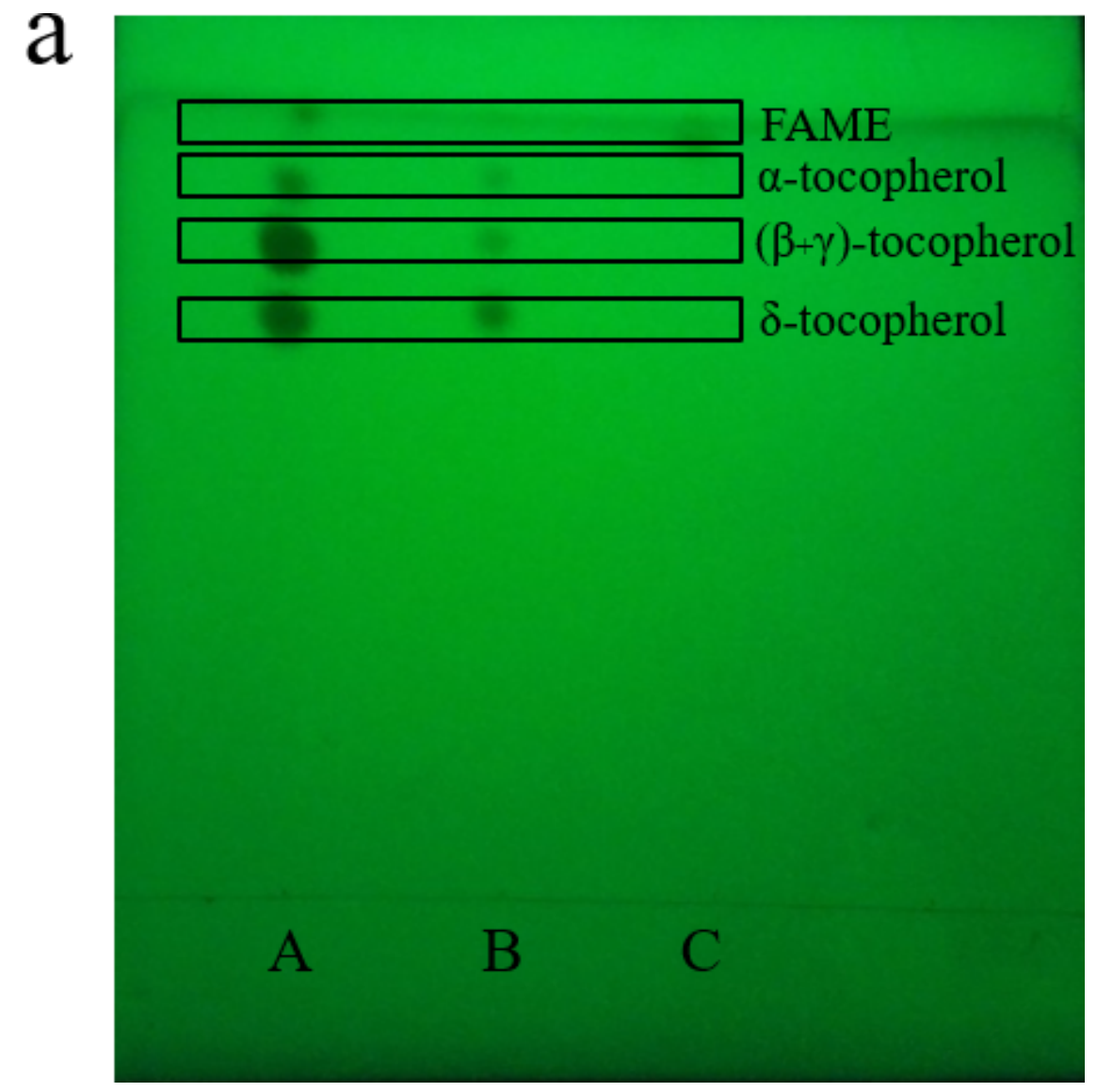




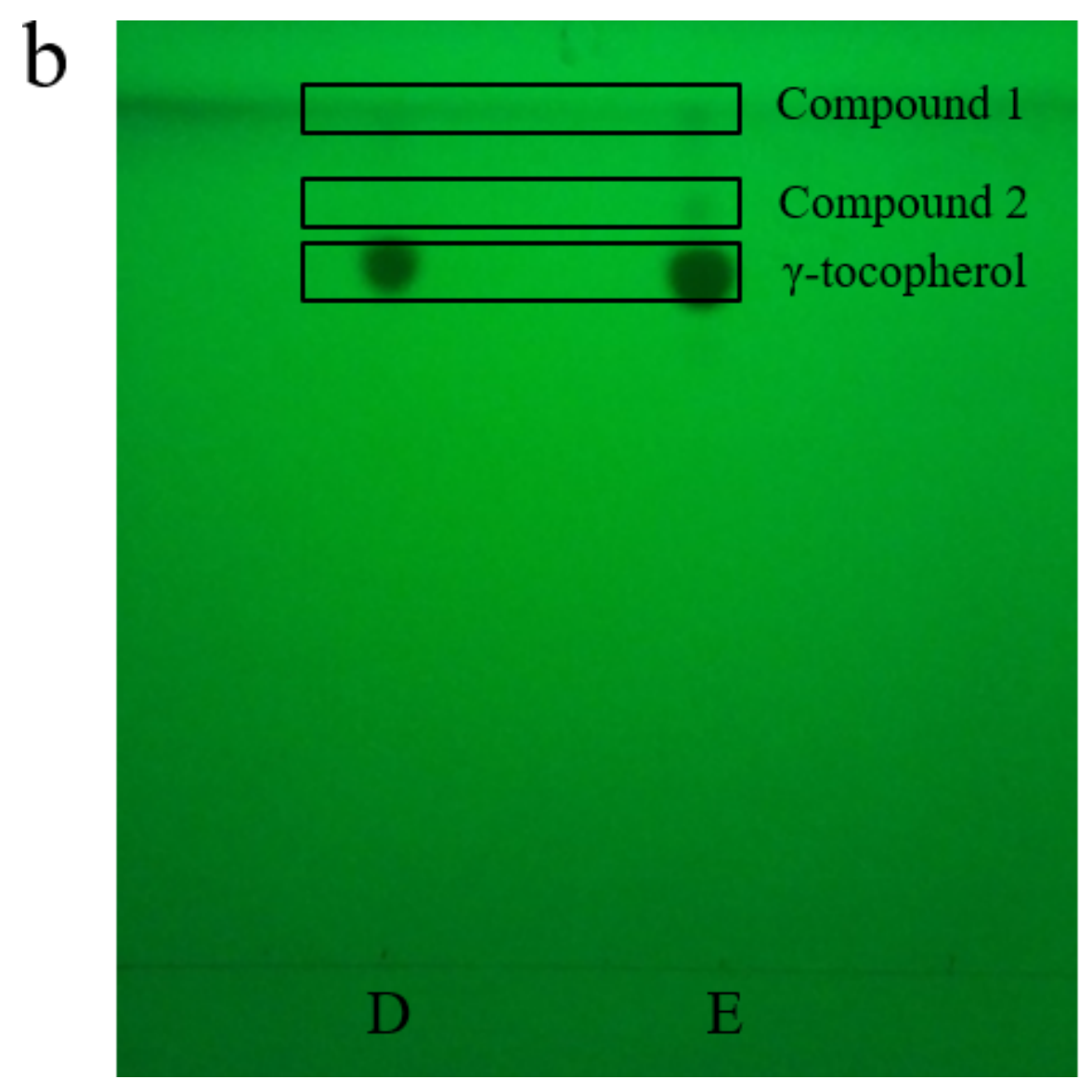

Fig. 3 

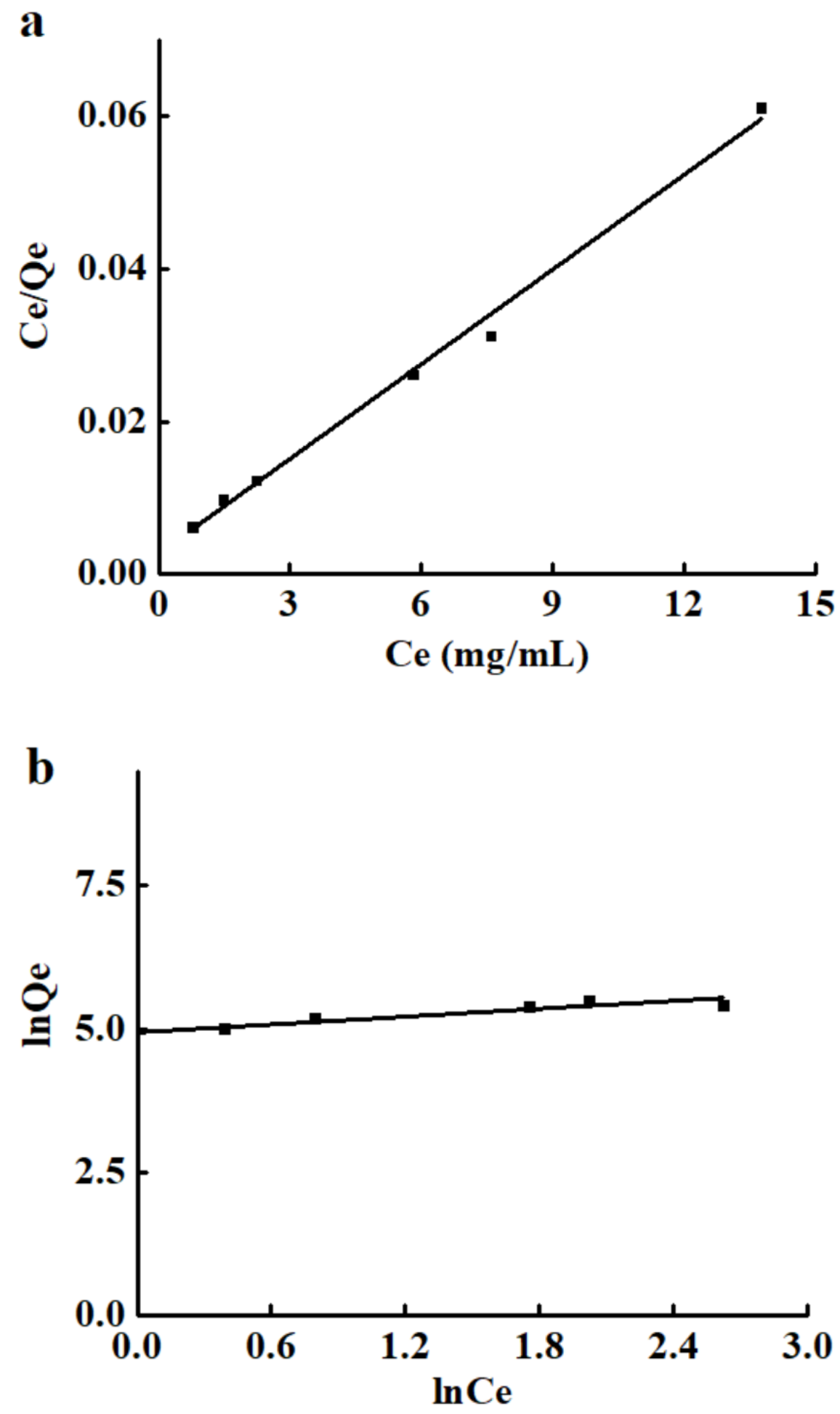

Fig. 4 

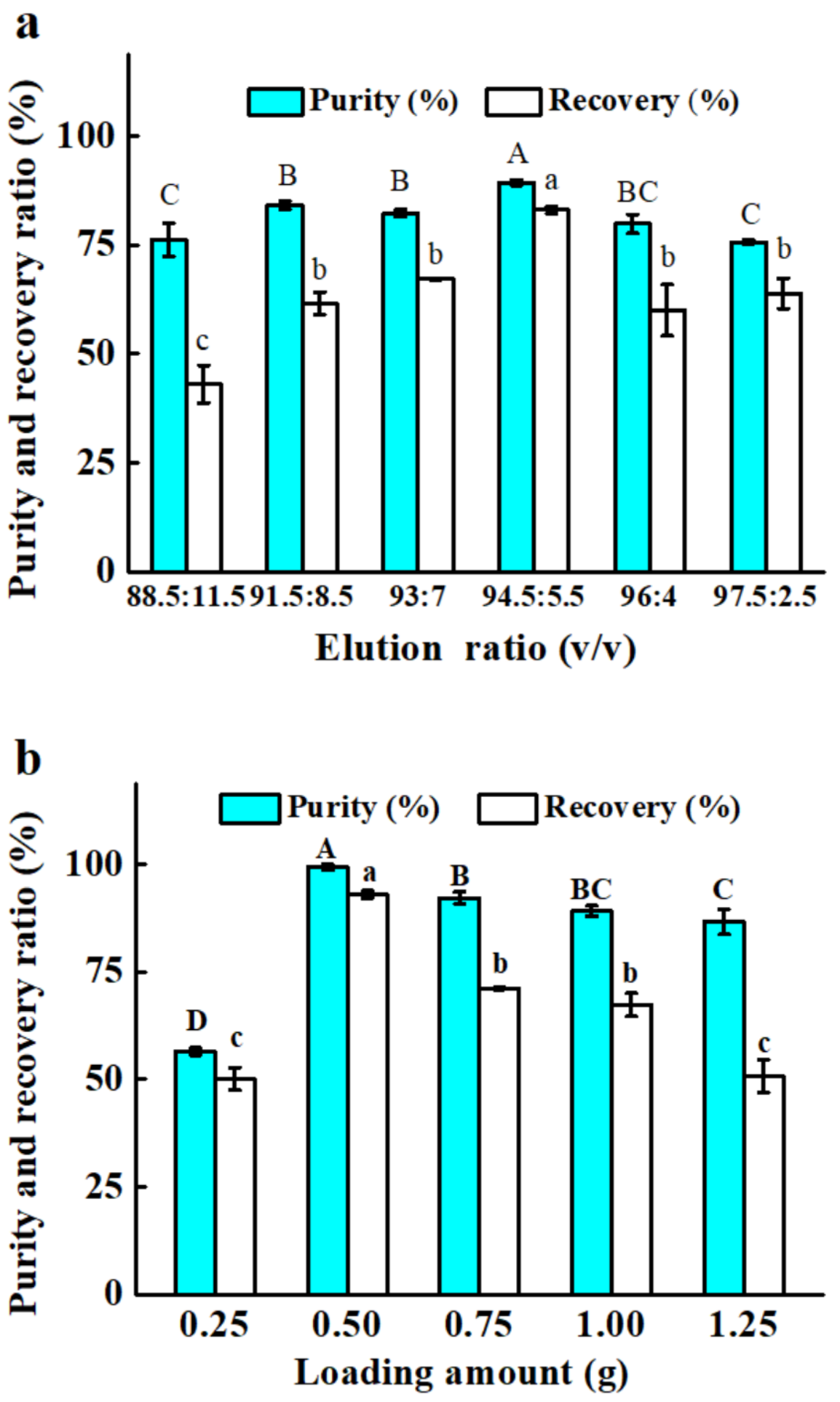

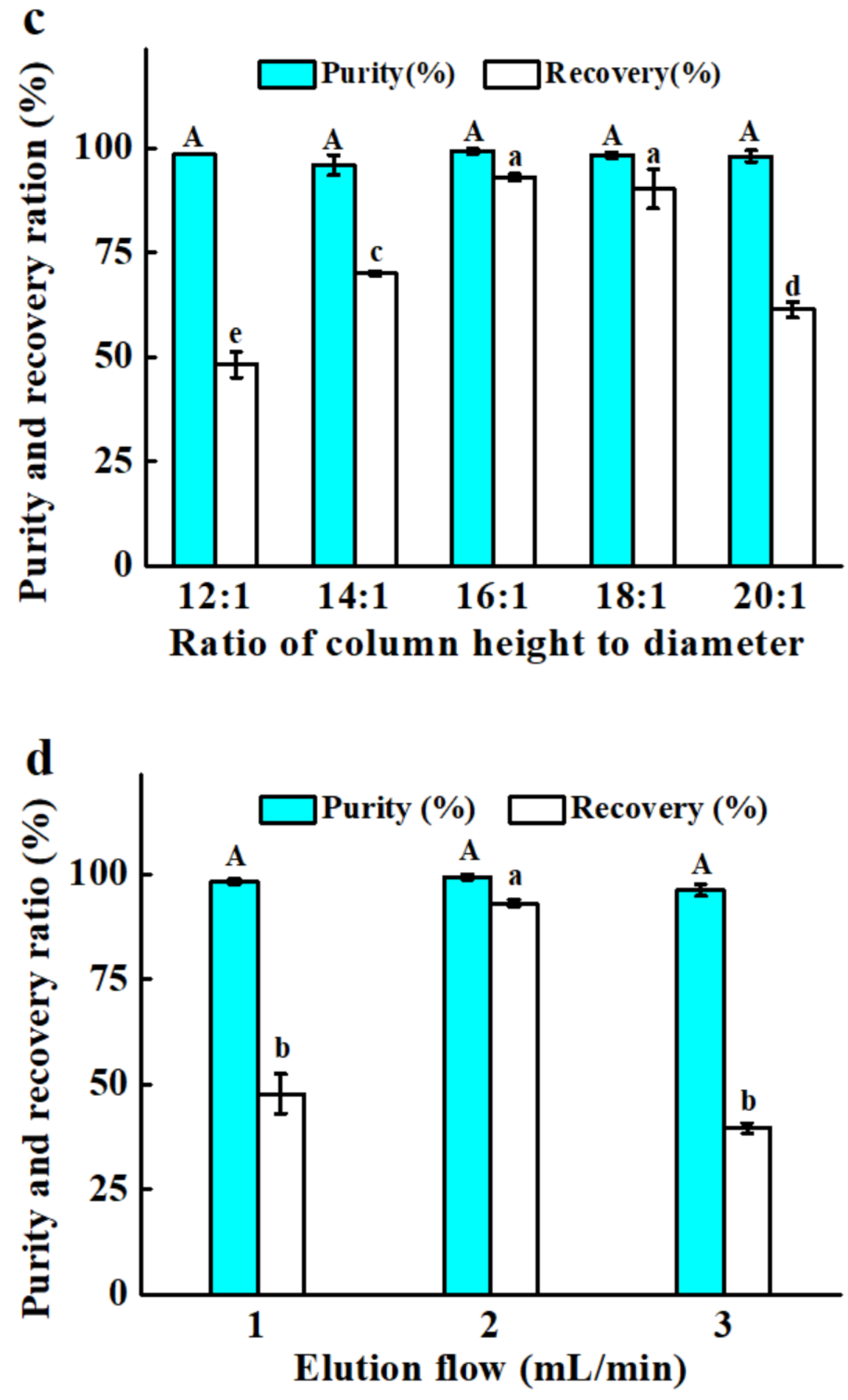

Fig. 5 



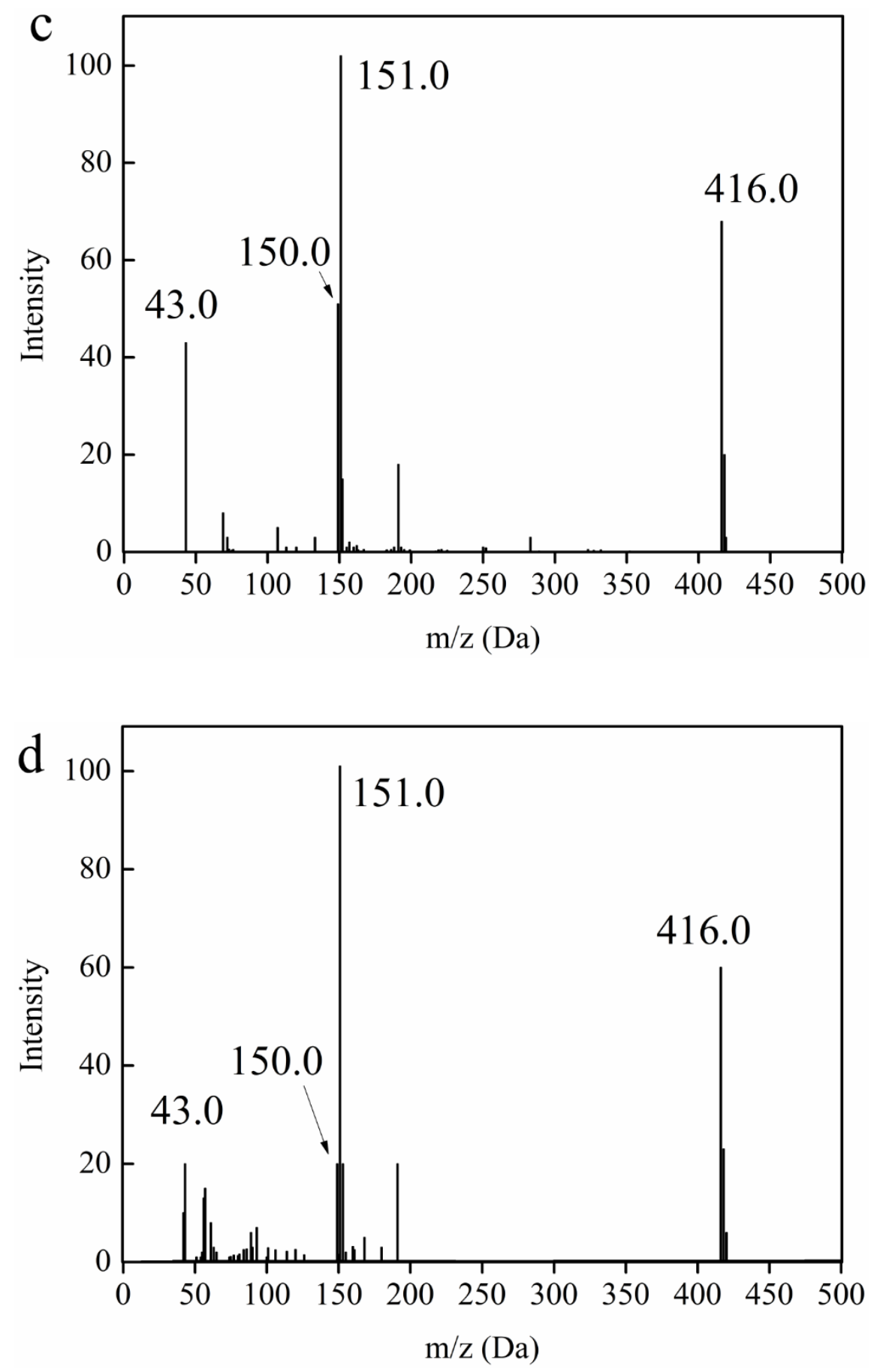